\title{
ABORDAGENS PRÁTICAS DE REVISÃO TEXTUAL DIALÓGICA NO ENSINO MÉDIO
}

\section{PRACTICAL APPROACHES OF DIALOGIC TEXTUAL REVISION IN HIGH SCHOOL}

\section{Denise Moreira Gasparotto* Renilson José Menegassi}

\section{RESUMO}

Este artigo discute abordagens do trabalho de revisão docente no ensino de produção textual escrita. A partir dos princípios da revisão na perspectiva dialógica (RUIZ, 2010, POSSATI, 2013; MENEGASSI e GASPAROTTO, 2016; 2019), apresenta-se uma proposta didática a essa abordagem, exemplificada e elucidada na produção escrita de um aluno de Ensino Técnico Integrado ao Ensino Médio. A proposta fundamenta-se nos pressupostos do dialogismo e na perspectiva da Análise Dialógica do Discurso (BAKHTIN/ VOLOCHÍNOV, [1929] 2009; BAKHTIN, [1979] 2010; BRAIT, 2012), da concepção de escrita como trabalho (GERALDI, 2011; FIAD e MAYRINK-SABINSON, 1991; MENEGASSI, 2016) e em pesquisas sobre revisão textual docente (HAYES, 2004; ALLAL et al., 2004; TRUPPIANO, 2006). Objetivou-se compreender i) como construir um bilhete de revisão efetivamente relacionado à perspectiva dialógica de linguagem; ii) quais os aspectos linguísticos e extralinguísticos implicados nessa produção escrita docente; iii) as alternativas de elaboração do bilhete de acordo com o objetivo de revisão; iv) a revisão para além da correção do texto em si, voltada à formação global do aluno no tocante ao discurso escrito, a compreender a qualidade da reescrita como parte do aprendizado sobre escrita pelo próprio aluno. Os resultados evidenciaram a revisão docente como uma produção textual a ser tomada em seu conjunto, a estabelecer relações entre bilhetes de revisão, objetivos de revisão, condições imediatas e mais amplas de trabalho; características fundamentais ao bilhete dialógico de revisão.

Palavras-chave: escrita; revisão docente; dialogismo.

\section{ABSTRACT}

This article discusses approaches for teacher's revision in written composition teaching. Based on the dialogic perspective revision assumptions' (RUIZ, 2010; POSSATI, 2013;

\footnotetext{
* Instituto Federal Catarinense, Campus Videira, IFC-Videira, Videira, SC. denisegasparotto@yahoo. com.br

Orcid: https://orcid.org/0000-0003-2990-9309

Artigo desenvolvido junto aos projetos de pesquisas "Práticas de revisão e reescrita de alunos de Ensino Médio: processos de apropriação pela intervenção docente" (UEM - processo 6111/2016, CAAE: 54133216.6.0000.0104), com fomento da FUMDES/UNIEDU e "Escrita, revisão e reescrita na formação docente", com fomento da Fundação Araucária, CP15/2017.

** Universidade Estadual de Maringá, UEM, Maringá, PR, Brasil. renilson@wnet.com.br.

Orcid: https://orcid.org/0000-0001-7797-811X
} 
MENEGASSI e GASPAROTTO, 2016; 2019), it is presented a didactic proposal to this approach, exemplified and elucidated in a composition from a High School Integrated to Technical Education student. The proposal is based on assumptions of the Discourse Dialogic Analysis (BAKHTIN/VOLOCHÍNOV, [1929] 2009; BAKHTIN, [1979] 2010; BRAIT, 2012), the writing conception as work (GERALDI, 2011; FIAD e MAYRINKSABINSON, 1991; MENEGASSI, 2016) and on teacher's textual revision researches (HAYES, 2004; ALLAL et al., 2004; TRUPPIANO, 2006). It was aimed to comprehend i) how to make a revision note effectively related to the language in dialogic perspective ii) which linguistic and extra linguistic aspects are implicated in this teacher's textual production; iii) the making notes alternatives according to the revision aim; iv) the revision beyond the text correction itself, focused on the global student formation concerning to written discourse, in order to comprehend the rewriting quality as part of writing learning by the student. The results showed the teacher's revision as a textual production to be taken in its totality, as to set relations among revision notes, revision aim, immediate and broader working conditions; dialogic revision note's fundamental features.

Keywords: writing; teacher's revision; dialogism.

\section{CONSIDERAÇÕES INICIAIS}

A produção textual escrita é tomada, em nossas pesquisas, sempre no âmbito de situação de ensino. $\mathrm{O}$ presente estudo volta-se à abordagem de práticas de revisão docente. As reflexões teórico-metodológicas respaldam-se no dialogismo, pela perspectiva da Análise Dialógica do Discurso (ADD) (BAKHTIN/ VOLOCHÍNOV, [1929] 2009; BAKHTIN, [1979] 2010; BRAIT, 2012); da escrita como trabalho (GERALDI, [1984] 2011; FIAD e MAYRINK-SABINSON, 1991; MENEGASSI, 2016); assim como em pesquisas sobre o trabalho docente de revisão textual (GARCEZ, 1998; SERAFINI, 2004; HAYES, 2004; ALLAL et al., 2004; TRUPPIANO, 2006; BREIDENBACH, 2006; RUIZ, 2010; POSSATI, 2013; GASPAROTTO e MENEGASSI, 2015; MENEGASSI e GASPAROTTO, 2016; 2019).

Tais pesquisas enfocam a necessidade de uma interação efetiva entre professor e aluno por meio da revisão, no sentido de promover o desenvolvimento de suas habilidades de escrita e de revisor de seu próprio discurso escrito. Dentre os estudos que discutem as metodologias de revisão (GARCEZ, 1998; HAYES, 2004; ALLAL et al., 2004; TRUPPIANO, 2006; POSSATI, 2013), há aqueles que abordam a construção do bilhete textual escrito pelo professor (SERAFINI, 2004; RUIZ, 2010; MENEGASSI; GASPAROTTO, 2016, 2019). A essa demanda, propõe-se compreender as particularidades da prática docente de revisão na perspectiva dialógica, especificamente, refletir sobre i) como construir um bilhete de revisão efetivamente nessa perspectiva analítica; ii) quais os aspectos linguísticos 
e extralinguísticos implicados nessa produção escrita docente; iii) as alternativas de elaboração do bilhete de acordo com o objetivo de revisão; iv) a revisão para além da correção do texto em si, voltada à formação global do aluno no tocante ao discurso escrito, a compreender a qualidade da reescrita como parte dos processos de ensino e aprendizagem sobre escrita pelo aluno.

A proposta de revisão foi construída a partir da primeira versão de um texto do gênero dissertação, produzido por um aluno de terceiro ano de um Curso Técnico Integrado ao Ensino Médio'. O texto foi produzido durante as aulas regulares de Língua Portuguesa e já havia passado pela revisão da professora, o que justifica as marcas de revisão nas imagens digitalizadas. O objeto de estudo foi apenas a primeira versão do texto do aluno e não a revisão feita pela professora. $\mathrm{O}$ que se espera, com o desenvolvimento deste trabalho, é a apontar possibilidades de abordagens à prática de revisão pelo docente na perspectiva dialógica que, de fato, promovam a interação por meio da revisão.

\section{DIALOGISMO, ESCRITA COMO TRABALHO E REVISÃO TEXTUAL DOCENTE}

A tríade teórico-metodológica que sustenta esta pesquisa tem como cerne o pressuposto do dialogismo, a partir de estudos do Círculo de Bakhtin (BAKHTIN/ VOLOCHÍNOV, [1929] 2009; BAKHTIN, [1979] 2010; VOLOCHÍNOV, [1926] 2013) ao refletir sobre a linguagem em caráter eminentemente social e suas relações sócio-valorativas. Respaldam este trabalho os estudos do dialogismo, no Brasil, pela perspectiva da Análise Dialógica do Discurso, doravante ADD (BRAIT, 2012), proposta ainda em consolidação no meio acadêmico, que reflete sobre o princípio dialógico da linguagem a partir da relação indissociável entre língua, linguagens, história e sujeito, em relações sociais valorativas; a tomar o texto como assinatura do sujeito, haja vista a mobilização de discursos históricos, sociais e culturais para a sua construção, em gêneros discursivos determinados.

O dialogismo é o princípio constitutivo da linguagem. Nenhum dizer é novo ou monológico, pois sempre é composto por múltiplas outras vozes que constituem o sujeito. As relações dialógicas são, portanto, ininterruptas, ocorrem em fluxo contínuo e se estabelecem a partir de um ponto de vista do sujeito social por natureza. A comunicação e a produção de sentidos só são possíveis por meio da interação entre um eu e um outro, sendo o outro nem sempre um sujeito conhecido

1. Registros do banco de dados do projeto de pesquisa "Escrita, revisão e reescrita na formação docente". 
ou presente fisicamente. Nessa interação, o dizer sempre é dirigido a alguém, ainda que seja a si mesmo, no diálogo interior. É nessa alteridade de dirigir a palavra ao outro e esperar dele uma resposta que se produzem os sentidos (BAKHTIN/ VOLOCHÍNOV, [1929] 2009).

Tomadas em seu caráter sócio-histórico, as relações dialógicas pressupõem, sempre, um contexto imediato de interação verbal, um contexto mais amplo que permeia a enunciação, assim como elementos axiológicos que incidem e são presentes diretamente no evento enunciativo e seus participantes. O extraverbal, junto à entoação e ao juízo de valor, são elementos tão pertinentes à significação do enunciado quanto o material linguístico. Aquilo que é explícito no enunciado, sua composição verbal, só é constituído de sentido por sua relação com os elementos extralinguísticos, que possibilitam a efetividade da interação entre interlocutores e a expressão da consciência socioideológica, em uma compreensão permeada pela entoação e pelas escolhas linguísticas (VOLOCHÍNOV, [1926] 2013).

A partir dessa compreensão axiológica, a palavra é tomada como signo ideológico. Sua escolha não se dá a priori, mas de acordo com as especificidades linguísticas e extralinguísticas da enunciação, a visar ao objetivo comunicativo. É ideológica porque é reveladora do caráter dialógico da linguagem (BAKHTIN/ VOLOCHÍNOV, [1929] 2009). Ao ser instrumento da interação entre o eи e o outro, a palavra é albeia ao ser ouvida ou lida pelo outro, e torna-se palavra minha ao ser externalizada por aquele que a recebeu, depois de processados os discursos dela oriundos. Isso ocorre porque, após ser ouvida ou lida, a palavra passa pelo discurso anterior do sujeito e é atravessada por suas vivências, seu juízo de valor, então é reelaborada e externalizada, a permear o processo de formação da consciência, que só ocorre pela linguagem (BAKHTIN/VOLOCHÍNOV, [1929] 2009).

$\mathrm{O}$ entendimento desses conceitos é fundamental à compreensão e à abordagem do dialogismo no escopo do ensino escolar, em especial aos processos de revisão e reescrita de textos. É o conhecimento teórico-metodológico, a percepção dos contextos imediato e mais amplo, e das axiologias inerentes à enunciação que sustentam o desenvolvimento de uma prática voltada à qualidade da interação, a promover meio favorável à alteridade, de modo que o aluno se desenvolva linguístico-textual-discursiva-social e ideologicamente dentro dos contextos sociais, dentre eles, os escolares.

Para atingir esse objetivo, todos os encaminhamentos no ensino de produção textual tomariam a escrita em seu processo, nunca um produto acabado da interação verbal. Breidenbach (2006) ressalta a não linearidade do processo de escrita e a 
necessidade de se romper o ideal de que há bons escritores por natureza, pois a escrita é esforço, uma habilidade a ser desenvolvida.

O cerne dessa concepção processual, cunhada no Brasil por Geraldi como escrita oriunda de trabalho efetivo (GERALDI, [1984] 2011²), é compreender a escrita como um acontecimento contínuo (TRUPPIANO, 2006), em que são relevantes todas as etapas de escrita, desde o planejamento até a última versão de reescrita, nas quais o professor atua como coautor, leitor, revisor, colaborador e o aluno é efetivamente reconhecido como sujeito autor de seu discurso. A escrita como trabalho "nos conduz a uma mudança de atitude - enquanto professores ante o aluno. Dele precisamos nos tornar interlocutores para, respeitando-lhe a palavra, agirmos como reais parceiros: concordando, discordando, acrescentando, questionando, perguntando, etc." (GERALDI, 2011, p. 128).

Sobre a demanda do diálogo contínuo, Antunes (2003) ressalta que é imprescindível que o aluno conheça o processo de produção escrita e que sejam proporcionados momentos de revisão e reescrita, a fim de que compreenda o caráter provisório e inacabado da escrita. Em suma, uma abordagem dialógica de escrita obrigatoriamente toma-a como processo, assim como uma prática pautada na escrita como processo, necessariamente, passa pelos processos de revisão e reescrita.

Uma forma de tornar a prática de escrita como trabalho produtiva, no que diz respeito ao domínio de habilidades linguísticas, textuais e discursivas pelo aluno e sua identificação como autor e conhecedor de seu dizer, é o enfoque na análise linguística em todo processo de escrita. A reescrita pode ser objeto de análise linguística, que pode levar a uma nova reescrita. Possati (2013) destaca que, numa concepção de escrita como trabalho, a produção textual, após sua primeira versão, já é constituída como objeto de análise linguística e que, ainda que o aluno não conheça a metalinguagem, é importante perceber os efeitos que se mobilizam de acordo com as revisões e reformulações realizadas em seu texto.

Refletir sobre o como o docente pode mediar a produção escrita do aluno é fundamental para as relações entre teoria dialógica e prática de sala de aula. Allal et al. (2004) ensinam que a revisão pode ser investigada em seus processos cognitivos e instrucionais, e que o processo instrucional não é mera aplicação do processo cognitivo. Ensinar o aluno a refletir sobre seu texto na perspectiva de leitor é um exemplo de instrução que pode ajudar quem escreve a ver globalmente seu texto, a atingir melhor nível de revisão (ALLAL et al., 2004). É preciso que os alunos

2. A referência consta em dois artigos específicos do livro: "Unidades básicas do ensino de português" e "Escrita, uso da escrita e avaliação". 
tenham oportunidade, por meio da reescrita, de aplicar as sugestões de revisão, sejam elas sobre o conteúdo do texto ou para afinar o discurso em relação ao leitor, para que o aprendizado processual seja ativado (KENN, 2010).

Hayes (2004) aponta a necessidade de pesquisas que investiguem o trabalho de mediação para ensinar o autor/aluno a revisar o próprio texto, tanto para reconhecer problemas quanto para identificar oportunidades de aprimoramento. Essa assertiva corrobora a visão de texto como assinatura de um sujeito histórico postulada pela ADD (BRAIT, 2012). Nesse processo, o professor proporciona "a sustentação que os aprendizes necessitam para resolver os múltiplos problemas das tarefas de composição e, desse modo, ir ultrapassando pouco a pouco os conhecimentos e procedimentos requeridos para se tornarem escritores autônomos" (CAMPS, 2006, p. 20). Assim, o autor, que também é revisor de seu texto, mobiliza e desenvolve concomitantemente sua consciência socioideológica e suas habilidades linguísticotextuais-discursivas.

Ao revisar o texto do aluno, seja por meio de bilhetes escritos ou oralmente, o docente precisa considerar uma série de fatores que determinam a qualidade da interação estabelecida entre ambos. O bilhete de revisão docente, isoladamente, não garante a qualidade da reescrita e o desenvolvimento de habilidades, haja vista o conjunto de elementos verbais e extraverbais (VOLOCHÍNOV, [1926] 2013) a serem considerados pelo professor revisor e a serem gradualmente compreendidos $\mathrm{e}$ internalizados pelo aluno. Entre eles, destacam-se: a) o conhecimento linguístico do aluno, b) o gênero discursivo solicitado no comando de produção, c) o tema sobre o qual se escreve, d) as valorações pertinentes ao tema e ao contexto de produção, e) a compreensão por professor e aluno da escrita como processo, f) a compreensão pelo aluno de o professor ser um colaborador, g) o auto reconhecimento pelo aluno como autor, h) a construção do sujeito revisor de seu próprio discurso, i) a motivação do aluno para a qualidade do projeto de dizer e j) a adequação do bilhete de revisão docente ao contexto de ensino.

Pesquisadores têm desenvolvido estudos que apresentem alternativas efetivas de construção da revisão docente. Serafini (2004) propõe as correções resolutiva, indicativa e classificatória. São alternativas a correções mais estruturais com enfoque nos desvios, mas que, se consideradas num conjunto de abordagens ou se combinadas a outras formas de revisão mais interativas, podem ser pertinentes e atingir a compreensão do aluno de modo satisfatório (MENEGASSI e GASPAROTTO, 2016). Com uma proposta voltada ao diálogo com o aluno e ao processo de colaboração docente, Ruiz (2010) orienta o uso da revisão textualinterativa, construída por meio de bilhetes textuais, que o docente pode deixar à 
margem ou ao final do texto do aluno, para tratar de desvios, possíveis melhorias no discurso ou mesmo do processo de aprendizagem de escrita do aluno.

Nascimento (2013), em proposição didática sobre revisão textual, compreende que, sejam quais forem, as práticas de linguagem de sala de aula são parcialmente fictícias, dado seu fim para aprendizagem. Nesse sentido, a autora defende os bilhetes orientadores como a abordagem que permite maior interação na revisão, a partir do qual se podem apontar ao aluno desde desvios estruturais específicos a desvios ou reflexões mais amplos.

Ao investigar o modo como esses bilhetes textuais podem ser elaborados pelo docente, Menegassi e Gasparotto (2016) apresentam o apontamento, o questionamento e o comentário como alternativas eficazes, e orientam, a partir da análise de revisões docente, os contextos mais favoráveis ao uso de cada uma dessas abordagens nos bilhetes. Em estudo sobre os princípios da revisão na perspectiva dialógica, Menegassi e Gasparotto (2019) reúnem as práticas docentes e discentes esperadas no ensino de produção textual pela perspectiva do dialogismo e da escrita como trabalho, como uma sistematização teórico-metodológica, a evidenciar as ações docentes primordiais:

- analisar constantemente a relação entre teoria e prática a partir das concepções de língua e de escrita nas quais se fundamenta;

- conhecer todas as etapas do processo de produção escrita e promover essa compreensão pelo aluno (ANTUNES, 2003);

- promover e avançar na qualidade da interação, ao considerar aspectos como contexto imediato, contexto mais amplo e elementos axiológicos da enunciação;

- assumir o papel de interlocutor virtual (GARCEZ, 1998), colaborador de um projeto de dizer, a promover alteridade e reconhecimento do e pelo aluno como sujeito autor (GERALDI, 2011);

- orientar o aluno à reflexão crítica sobre as intervenções de revisão docente, palavra albeia, por meio do juízo de valor, a colocar-se como autor e revisor de seu discurso, a elaborar a palavra minha;

- promover ousadia na revisão pelo aluno, a fim de que reflita e considere possíveis reformulações para além das sugestões do docente (MENEGASSI, 1998; HAYES, 2004);

- diversificar as abordagens de revisão conforme as especificidades do contexto de trabalho e o processo de aprendizagem de cada aluno (LEAL, 2003), entre elas: a revisão coletiva, a revisão em pares (RUIZ, 2010), a revisão tardia pelo próprio autor, o atendimento individualizado (TRUPPIANO, 2006) e a construção 
de bilhetes textual-interativos sob a forma de comentários, apontamentos ou questionamentos (MENEGASSI, GASPAROTTO, 2016);

- acompanhar o desenvolvimento de habilidades de escrita do aluno e avançar nas abordagens de revisão, no intuito de promover o desenvolvimento da consciência discursiva e a autonomia no processo de revisão.

Assim, os pressupostos do dialogismo, especificamente no que tangem à interação, ao outro e aos elementos valorativos, são fundamentais para se refletir a escrita como processo (FIAD e MAYRINK-SABINSON, 1991; MENEGASSI, 2016). E, nesse escopo, os estudos cognitivistas (HAYES, 2004; CAMPS, 2006) contribuem para a compreensão dos processos e etapas intercambiáveis da construção do texto escrito (BREIDENBACH, 2006), a ser um dos alicerces para a reflexão, pela perspectiva dialógica, sobre o processo de ensino-aprendizagem da escrita, a culminar, dentre outras contribuições, em proposições metodológicas de trabalho com a revisão e a reescrita de textos com vistas ao desenvolvimento de habilidades linguístico-discursivas de escrita pelo aluno (RUIZ, 2010; TRUPPIANO, 2006; MENEGASSI; GASPAROTTO, 2016).

\section{ABORDAGENS PRÁTICAS DE REVISÃO DIALÓGICA}

O texto utilizado para elucidar a proposta de revisão dialógica pelo docente é a primeira versão da dissertação sobre o tema Intolerância nas redes sociais, produzida por um aluno de 16 anos, concluinte do Curso Técnico em Informática Integrado ao Ensino Médio, no Instituto Federal Catarinense, em câmpus situado no Meio-Oeste do estado. Apresenta-se, inicialmente, a digitalização da versão completa do texto, para melhor compreensão do trabalho de escrita do aluno. A digitalização contém marcas de revisão da docente de Língua Portuguesa, que não são objeto de análise neste trabalho, tendo em vista a intenção de apontar caminhos para a construção de bilhetes de revisão dialógica. Para a posterior apresentação da proposta de revisão, o texto foi digitado e separado por parágrafos, para que cada bilhete de revisão proposto fosse explicitado. 
Dissertação sobre a intolerância nas redes sociais $-1^{\text {a }}$ versão

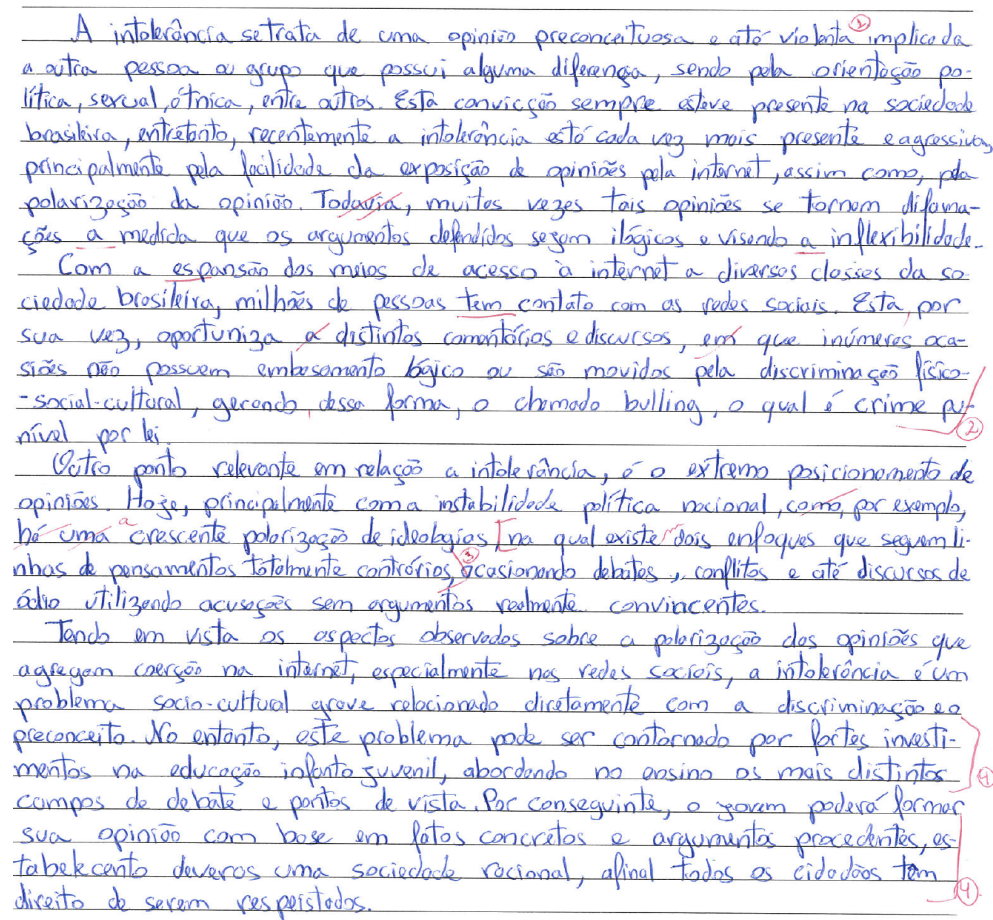

O que se apresenta, a seguir, é uma proposta de abordagens para a revisão dialógica da dissertação produzida, com bilhetes que pretendam atender aos princípios do dialogismo e que visem ao desenvolvimento da consciência discursiva do aluno. Para tanto, temos consciência dos riscos implicados na proposta, como a parcialidade possível dela decorrente.

Sobral (2009) orienta que a formação da consciência ocorre na interação por meio da linguagem e que há diferentes níveis que podem ser alcançados e incidem sobre o processo de formação da consciência. Uma revisão dialógica, nesse escopo, é a que avança nos níveis de interação com vistas ao desenvolvimento do sujeito na escrita de textos. A nosso ver, dentre as várias orientações identificadas na literatura apresentada na seção teórica, um bilhete dialógico de revisão deve abarcar seis aspectos essenciais: i) o diálogo colaborativo por meio do reconhecimento do aluno como autor; ii) a abordagem de metodologias e escolhas linguísticas, ao escrever o bilhete textual, que promovam a reflexão pelo aluno, no sentido de formá-lo revisor de seu próprio discurso; iii) a adequação da abordagem escolhida ao contexto imediato e ao contexto mais amplo, como o gênero discursivo produzido e o nível 
de aprendizagem do aluno; iv) o reconhecimento e a mobilização das axiologias que permeiam o evento enunciativo da revisão; v) um conjunto de revisões que apontem desvios linguísticos e discursivos, mas que também promova o desenvolvimento da consciência socioideológica do sujeito por meio da linguagem; vi) a atenção ao processo e ao progresso individual de aprendizagem do aluno, que pode, por exemplo, ser comentada nos bilhetes textuais.

$\mathrm{Na}$ sequência, a proposta de abordagem de revisão ao primeiro parágrafo do texto.

Quadro 1. Dissertação sobre intolerância nas redes sociais - Excerto 1.

\begin{tabular}{|c|c|}
\hline $1^{\circ}$ parágrafo & Proposta de revisão \\
\hline $\begin{array}{l}\text { A intolerância se trata de uma opinião } \\
\text { preconceituosa e até violenta(1) implicada a } \\
\text { outra pessoa ou grupo }(2) \text { que possui alguma } \\
\text { diferença, sendo pela orientação política, social, } \\
\text { étnica, entre outros. Esta convicção(3) esteve } \\
\text { presente na sociedade brasileira, entretanto, } \\
\text { recentemente a intolerância está cada vez } \\
\text { mais presente e agressiva principalmente } \\
\text { pela facilidade da exposição de opiniões } \\
\text { pela internet, assim como, pela polarização } \\
\text { da opinião. Todavia(4), muitas vezes tais } \\
\text { opiniões se tornam difamações a medida que os } \\
\text { argumentos definidos sejam ilógicos e visando a } \\
\text { inflexibilidade. }\end{array}$ & $\begin{array}{l}\text { 1. Léo, tente explicar melhor esta afirmação. O } \\
\text { que você quer dizer com "opinião violenta"? } \\
\text { 2. O uso de "implicada" também não me pareceu } \\
\text { adequado aqui. } \\
\text { 3. A intolerância é uma convicção? } \\
\text { 4. Este conectivo é usado para introduzir uma } \\
\text { oposição ao que foi dito antes, o que não ocorre } \\
\text { neste contexto. Veja se pode substituir ou omiti- } \\
\text { lo. Penso que todo o período pode ser revisado, } \\
\text { visando à melhor compreensão pelo leitor. }\end{array}$ \\
\hline
\end{tabular}

Os bilhetes 1, 2 e 3, semelhantes entre si, tratam, respectivamente, do uso das palavras "violenta", "implicada" e "convicção". É frequente o docente identificar expressões inadequadas ao contexto de escrita ou ao tema. Palavras que não podem ser afirmadas como incorretas, mas que parecem não alcançar o significado pretendido pelo autor. Nesses casos, a revisão por meio de questionamento é uma intervenção bastante pertinente, especialmente quando se identificam lacunas na compreensão pelo leitor, o que pode ser corrigido pelo acréscimo de informações ou pela substituição por expressões mais adequadas (MENEGASSI; GASPAROTTO, 2016).

O questionamento possibilita que o aluno autor veja na figura do professor colaborador também um leitor de seu texto. Na revisão 1, "Léo, tente explicar melhor esta afirmação. O que você quer dizer com 'opinião violenta'?", apenas o apontamento, que solicita melhor explicação sobre a afirmação, poderia estabelecer bom nível de interação com o aluno a ponto de ele reformular adequadamente o trecho, uma 
vez que o professor dialoga com o aluno, a responder a interação estabelecida na reescrita posterior, a causar o efeito de bom nível de interação, um elemento aqui constituído como provável. O recurso do questionamento para completar a revisão cumpre a função de trazer ao aluno a figura do outro, do interlocutor real (GARCEZ, 1998): "o que você quer dizer com 'opinião violenta'?". O conjunto do bilhete de revisão mostra que não é apenas um desejo do professor que o conceito de opinião violenta seja mais bem explicado, mas que este, no processo de colaboração (GERALDI, 2011; MENEGASSI; GASPAROTTO, 2016), alerta para algo que pode soar estranho ou incompreensível ao leitor, a propor um diálogo colaborativo por meio do reconhecimento do aluno como autor, o que se reitera com o uso do vocativo.

Ao introduzir essa revisão completa, que aponta o desvio e questiona a relação entre o sentido produzido e o pretendido, os bilhetes 2 e 3 tornam-se complementares e podem ser mais sucintos, tomados como continuação do diálogo estabelecido na revisão 1. O bilhete 2, "o uso de 'implicada' também não me pareceu adequado aqui", é uma afirmação que alerta o aluno de que se trata de um desvio de mesma natureza que o desvio 1. A palavra "implicada" também não é adequada ao contexto, como ocorreu com a palavra "violenta". Na sequência desse diálogo, ao identificar um período confuso à compreensão pelo leitor, bilhete 3 , o docente, em vez de repetir a afirmação de que há uma palavra com uso inadequado, retoma sua fala como leitor e questiona: "a intolerância é uma conviç̧ão?". Aqui, ao invés de uma assertiva sobre o erro, o questionamento fecha o conjunto das três revisões, a devolver a palavra ao autor (GERALDI, 2011), a alternar o turno para que ele, como conhecedor de seu discurso, reflita e exerça seu juízo de valor (VOLOCHÍNOV, [1926] 2013) sobre o que lhe foi apontado e questionado.

A análise desses bilhetes, em conjunto, evidencia a prática de revisão docente como uma produção textual por si. Para ser dialógica, a revisão precisa ser tomada em sua totalidade, por meio do reconhecimento do processo de interação existente entre aluno-texto-revisão-professor, a possibilitar, por exemplo, o uso de bilhetes sucintos, mas, ainda assim, dialógicos, haja vista a completude de sentido possível por meio do diálogo que se estabelece nas retomadas, nos vocativos, nos questionamentos que, no todo, têm a função de apontar ao aluno que a revisão se efetiva no âmbito discursivo, isto é, a forma fragmentada de abordar os desvios é apenas um caminho estratégico para a revisão global do texto. No exemplo apresentado, a revisão propõe-se dialógica ao primar por metodologias e escolhas linguísticas, ao escrever o bilhete textual, que promovem a reflexão pelo aluno, no sentido de formá-lo revisor de seu próprio discurso; e ao propor um conjunto 
de revisões que apontam desvios linguísticos e discursivos, mas que também promovem o desenvolvimento da consciência socioideológica do sujeito por meio da linguagem (HAYES, 2004; SOBRAL, 2009; KENN, 2010; MENEGASSI; GASPAROTTO, 2019).

No bilhete 4 da legenda, tem-se uma inadequação que altera o sentido do discurso e gera uma incoerência, ao se usar a conjunção adversativa "todavia" para introduzir um período com efeito de sentido aditivo: "Este conectivo é usado para introduzir uma oposição ao que foi dito antes, o que não ocorre neste contexto. Veja se pode substituir ou omiti-lo. Penso que todo o período pode ser revisado, visando à melhor compreensão pelo leitor". Diferente das revisões anteriores, esta trata não apenas da produção de sentido, mas, também, de conhecimento linguístico. Usar a revisão para apontar o desvio e, complementarmente, ensinar sobre o aspecto apontado é promover análise linguística a partir da construção discursiva do aluno (GERALDI, 2011; POSSATI, 2013), o que favorece a aquisição de novos conhecimentos linguísticos e o desenvolvimento da consciência discursiva pelo sujeito. O bilhete 4 propõe-se dialógico ao apontar e explicar sobre o desvio: "Este conectivo é usado para introduzir uma oposição ao que foi dito antes, o que não ocorre neste contexto", e sugerir caminhos para a revisão pelo aluno, "Veja se pode substituir ou omiti-lo. Penso que todo o período pode ser revisado, visando à melhor compreensão pelo leitor". Assim, devolve-se a palavra ao sujeito para que, como autor, estabeleça juízo de valor (VOLOCHÍNOV, [1926] 2013) sobre a revisão e marque na reescrita seu processo de autoria, ao apresentar sua escolha linguísticodiscursiva para reformulação do excerto (MENEGASSI; GASPAROTTO, 2019). Além do papel de colaborador e do reconhecimento do aluno autor, o bilhete busca adequar-se ao contexto imediato e ao contexto mais amplo, a atentar-se não apenas à correção do desvio, mas à apresentação de novos conhecimentos, abordada de forma adequada ao nível de aprendizagem do aluno (POSSATI, 2013). 
Quadro 2. Dissertação sobre intolerância nas redes sociais - Excerto 2.

\begin{tabular}{|c|c|}
\hline $2^{\circ}$ parágrafo & Proposta de revisão \\
\hline $\begin{array}{l}\text { Com a espansão* dos meios de acesso à internet } \\
\text { a diversas classes da sociedade brasileira, } \\
\text { milhões de pessoas tem }(5) \text { contato com as } \\
\text { redes sociais. Esta por sua vez, oportuniza } \\
\text { a distintos comentários e discursos, em que } \\
\text { inúmeras ocasiões não possuem embasamento } \\
\text { lógico ou são movidos pela discriminação físico- } \\
\text { social-cultural, gerando dessa forma, o chamado } \\
\text { bulling*, o qual é crime punível por lei( } 6 \text { ). }\end{array}$ & $\begin{array}{l}\text { 5. Revise a concordância. } \\
\text { 6. É preciso revisar atentamente esse período de } \\
\text { modo que sua argumentação seja mais objetiva } \\
\text { e compreensível ao leitor. Você pode retomar o } \\
\text { sentido que gostaria de trazer e refletir a melhor } \\
\text { forma de apresentá-lo, no conjunto do parágrafo. } \\
\text { Para auxiliá-la nessa tarefa, aponto: } \\
\text { - oportunizar é um verbo que costuma } \\
\text { introduzir informações positivas. Não acho que } \\
\text { ele seja adequado aqui; } \\
\text { - revise a regência dos trechos em destaque, há } \\
\text { preposições desnecessárias; } \\
\text { - há duas expressões que, se mantidas na sua } \\
\text { reescrita, devem ficar entre vírgulas. }\end{array}$ \\
\hline
\end{tabular}

O bilhete 5 é um breve apontamento para que o aluno use o plural do verbo "ter". O uso do imperativo em "revise a concordância" assemelha-se à revisão classificatória proposta por Serafini (2004), na qual se apresenta apenas a natureza do desvio. Para a efetividade dessa interação, o aluno tanto pode ter apenas esquecido de colocar acento para indicar o plural do verbo, como pode não saber pluralizá-lo, pois o apontamento solicita revisão pelo autor, que deve refletir e pesquisar formas de corrigir o desvio. Assim, essa abordagem não seria dialógica apenas se o aluno não soubesse o que é um desvio de concordância. Aqui, ao tomar os elementos extraverbais à revisão, o docente considerou o nível de escolaridade do aluno, concluinte do Ensino Médio (GASPAROTTO; MENEGASSI, 2015), e pressupôs conhecimento metalinguístico prévio necessário à compreensão da revisão (POSSATI, 2013).

O exemplo reitera que uma abordagem é caracterizada na perspectiva dialógica de acordo com a efetividade da interação estabelecida (SOBRAL, 2009), consideradas as circunstâncias linguísticas e extralinguísticas, imediatas e mais amplas nas quais ocorre a enunciação. Não se trata de quantidade ou de extensão de bilhetes de revisão, assim como, na reescrita, não se trata se quantidade de reformulações (RIJLAARSDAM et al., 2004).

No bilhete 6, tem-se o processo oposto ao apontamento 5. Trata-se de um comentário de revisão que aponta o desvio, justifica-o, a fim de que o aluno compreenda onde e por que há uma inadequação, e sugere alternativas para solucionar o problema apresentado (CAMPS, 2006). Algumas palavras foram 
sublinhadas no texto do aluno, contudo, todo o período fica confuso ao leitor. A apresentação de uma correção resolutiva, que redija ao aluno uma forma de reescrever o período, levaria a um resultado adequado, porém não dialógico propriamente, ao desconsiderar o processo de reflexão sobre a construção do texto (POSSATI, 2013). Faz-se necessário construir um bilhete que convoque o autor à reflexão sobre os sentidos produzidos e seu objetivo comunicativo, ao que se orienta: "É preciso revisar atentamente esse período de modo que sua argumentação seja mais objetiva e compreensivel ao leitor". Aqui, tem-se uma configuração relevante do bilhete dialógico, sobretudo ao se tratar de desvios relacionados à argumentação. $\mathrm{O}$ bilhete é formado por i) apresentação do desvio (há um problema na argumentação); ii) justificativa, a fim de que o aluno compreenda o motivo da inadequação (o argumento não está compreensível ao leitor). Esses seriam dois elementos fundamentais à compreensão pelo aluno. Somado a estes, o docente faz um apontamento de iii) evocação da figura do autor (é preciso retomar o sentido que se pretendeu e comparar com o que foi escrito).

É possível que essa revisão já fosse suficiente para compreensão e reescrita adequadas, a depender do processo de aprendizagem do aluno, tendo em vista o caráter heterogêneo de uma classe, ainda que os alunos frequentem o mesmo estágio do curso. No exemplo, considerou-se a possibilidade de o aluno, apesar de compreender que há um desvio, não saber como corrigi-los, já que são habilidades distintas, como destaca Hayes (2004). Nesse sentido, o docente assume-se coautor daquele projeto de dizer (GERALDI, 2011), a partir da iv) apresentação de reflexões, por meio de perguntas ou afirmações, que apontem caminhos para o modo como o excerto pode ser reformulado: "Para auxiliá-lo nessa tarefa, aponto: oportunizar é um verbo que costuma introduzir informações positivas. Não acho que ele seja adequado aqui, - revise a regência dos trechos em destaque, bá preposições desnecessárias; - bá duas expressões que, se mantidas na sua reescrita, devem ficar entre vírgulas".

Em síntese, esse comentário de revisão desenvolve o autor e o revisor (HAYES, 204; MENEGASSI; GASPAROTTO, 2019); promove autonomia no processo de escrita; abre possibilidades para reformulações além das solicitadas (MENEGASSI, 1998), que marquem o estilo, a autoria, a ultrapassar o objetivo da reescrita correta, com adequação linguística e atendimento ao comando de produção, e a promover o desenvolvimento da consciência por meio da linguagem (BAKHTIN/VOLOCHÍNOV, [1929] 2009; KENN, 2010). 
Quadro 3. Dissertação sobre intolerância nas redes sociais - Excerto 3.

\begin{tabular}{|c|c|}
\hline $3^{\circ}$ parágrafo & Proposta de revisão \\
\hline $\begin{array}{l}\text { Outro ponto relevante em relação a } \\
\text { intolerância(7), é o extremo posicionamento } \\
\text { de opiniões(8). Hoje, principalmente com } \\
\text { a instabilidade política nacional, como, por } \\
\text { exemplo }(9) \text {, há uma crescente polarização de } \\
\text { ideologias, na qual existe(5) dois enfoques } \\
\text { que seguem linhas de pensamentos totalmente } \\
\text { contraditórios(10), ocasionando debates, } \\
\text { conflitos e até discursos de ódio } \\
\text { acusações sem argumentos realmente } \\
\text { convincentes. }\end{array}$ & $\begin{array}{l}\text { 7. Revise a regência nesse trecho. } \\
\text { 8. O que seria "extremo posicionamento"? Não } \\
\text { entendi. } \\
\text { 9. Pode ser suprimido. Há algumas expressões e } \\
\text { conectivos ao longo do texto que, se suprimidos, } \\
\text { podem trazer mais precisão e organização ao seu } \\
\text { discurso. Considere isso ao revisar todo o texto. } \\
\text { 5. Concordância } \\
\text { 10. A polarização já não indica contradição? } \\
\text { Achei repetitivo esse período. Veja o que acha. } \\
\text { 11. Você pretende apresentar consequências } \\
\text { ruins da polarização de ideologias. Essas palavras } \\
\text { têm, todas, efeito de sentido negativo? }\end{array}$ \\
\hline
\end{tabular}

O terceiro parágrafo da dissertação apresenta desvios linguísticos, como elucida o bilhete 5, que retoma a legenda já utilizada para um desvio apontado no primeiro parágrafo, para que se revise a concordância; e também o bilhete 7 , que considera um conhecimento metalinguístico prévio do aluno para a compreensão da revisão e adequada correção, por meio da substituição.

Os desvios discursivos desse parágrafo, em sua maioria, permitem intervenções pontuais, o que ocorre nos bilhetes 8,10 e 11 . Assim como no primeiro parágrafo, foram identificadas pelo professor algumas afirmações ou expressões que comprometem a compreensão do texto pelo leitor e, consequentemente, a argumentação, tão relevante na dissertação. Para indicar tais incoerências ou lacunas, usa-se, novamente, a abordagem do questionamento, "O que seria 'extremo posicionamento'?", para alertar ao autor que o leitor tem dificuldades para compreender aquele argumento. Esses questionamentos são acompanhados por afirmações breves que ratificam o interesse do leitor pelo texto, como em "não entendi", ou a figura de coautor do docente, como em "Achei repetitivo esse período. Veja o que acha". Trata-se de uma abordagem que convida ao diálogo, à negociação de sentidos, pois é um questionamento que, mais do que provocar, espera do outro uma resposta, é um questionamento que solicita melhores explicações, por um leitor interessado no texto (MENEGASSI e GASPAROTTO, 2016). 
Quadro 4. Dissertação sobre intolerância nas redes sociais - Excerto 4.

\begin{tabular}{|c|c|}
\hline $4^{\circ}$ parágrafo & Proposta de revisão \\
\hline $\begin{array}{l}\text { Tendo em vista os aspectos observados sobre a } \\
\text { polarização das opiniões que agregam coerção } \\
\text { na internet, especialmente nas redes sociais, a } \\
\text { intolerância é um problema sócio-cultural grave } \\
\text { relacionado diretamente com a discriminação e } \\
\text { o preconceito. No entanto, este problema pode } \\
\text { ser contornado por fortes investimentos na edu- } \\
\text { cação infanto juvenil*, abordando no ensino os } \\
\text { mais distintos campos de debate e pontos de } \\
\text { vista. Por conseguinte, o jovem poderá formar } \\
\text { sua opinião com base em fatos concretos e ar- } \\
\text { gumentos procedentes, estabelecendo deveras } \\
\text { uma sociedade nacional, afinal todos os cidadãos } \\
\text { têm direito de serem respeitados(12). }\end{array}$ & $\begin{array}{l}\text { 12. Sua conclusão está muito bem organizada, } \\
\text { mas é preciso melhorar a proposta de interven- } \\
\text { ção com informações mais específicas sobre o } \\
\text { que pode ser feito. Deixo algumas perguntas } \\
\text { para lhe ajudar nessa reflexão: } \\
\text { - É pertinente uma intervenção apenas na } \\
\text { educação infanto-juvenil? Como lidar com } \\
\text { o problema da intolerância no restante da } \\
\text { população? } \\
\text { - Como podem ser aplicados esses investi- } \\
\text { mentos? Será somente na escola? Qual será a } \\
\text { abordagem? } \\
\text { currículo, projetos, mídia) } \\
\text { - Qual a responsabilidade das redes sociais nos } \\
\text { discursos de ódio que por meio delas é propa- } \\
\text { gado? } \\
\text { * Revisar ortografia. }\end{array}$ \\
\hline
\end{tabular}

O último comentário, bilhete 12, trata da conclusão do texto, correspondente a todo parágrafo do Quadro 4. Quando se trata de argumentação, é preciso ensinar o caminho ao aluno. É possível que, para ele, a informação apresentada já seja suficiente como força de argumento. Nesses casos, geralmente não há dificuldade na compreensão das informações pelo leitor. $O$ foco da revisão é a melhoria da argumentação (KENN, 2010), o convencimento do leitor, mais do que a compreensão, isto é, o alcance do objetivo do texto dissertativo, uma das responsabilidades do professor. Assim, além de aspectos linguísticos ou organização do discurso, visa-se ao desenvolvimento da consciência sobre o tema pelo sujeito autor, que deve olhar criticamente para a construção linguística do seu texto, num contexto imediato, mas também no discurso que assume como autor sobre aquele tema, num contexto mais amplo, como era a proposta da dissertação produzida. A estratégia de revisão proposta é semelhante à apresentada no bilhete 6, com diálogo sobre os sentidos produzidos e os efeitos destes ao objetivo comunicativo, "Sua conclusão está muito bem organizada, mas é preciso melhorar a proposta de intervenção com informações mais específicas sobre o que pode ser feito". O comentário docente é como se alertasse: "seu discurso é compreensível ao leitor, ainda assim pode não convencê-lo sobre seu ponto de vista". Como o discurso argumentativo é, comumente, uma habilidade em desenvolvimento pelo aluno de nível médio, usam-se questionamentos sobre os argumentos apresentados 
pelo autor, por exemplo, "Como podem ser aplicados esses investimentos?". As perguntas visam evidenciar lacunas de informações que tornam os argumentos frágeis, pouco convincentes (MENEGASSI; GASPAROTTO, 2016): "É pertinente uma intervenção apenas na educação infanto-juvenil? Como lidar com o problema da intolerância no restante da população?".

A legenda marcada com asterisco, ao final dos comentários, indica que as palavras assim identificadas, ao longo do texto, demandam revisão ortográfica. É um apontamento breve e suficiente ao aluno desse nível de aprendizagem, pois, ainda que não saiba como escrever corretamente a palavra, sabe que deve buscar essa informação para proceder à substituição na reescrita. No caso de alunos em fase aprendizagem do código escrito, como no Ensino Fundamental I, outro caso de ensino de escrita, uma revisão mais completa poderia ser mais dialógica e ensinar ao aluno sobre a grafia correta das palavras. Isso reitera a necessidade de a revisão adequar-se às variáveis do evento enunciativo, dentre elas, o conhecimento linguístico do aluno e o nível de ensino-aprendizagem em que se encontra (POSSATI, 2013; GASPAROTTO e MENEGASSI, 2015).

Para melhor compreensão da abordagem proposta de revisão dialógica construída, apresenta-se o texto completo com as intervenções de revisão elaboradas e analisadas neste trabalho, como sugestões possíveis das relações teórico-práticas aqui discutidas.

\section{Quadro 5. Proposta de revisão dialógica.}

A intolerância se trata de uma opinião preconceituosa e até violenta(1) implicada a outra pessoa ou grupo(2) que possui alguma diferença, sendo pela orientação política, social, étnica, entre outros. Esta convicção(3) esteve presente na sociedade brasileira, entretanto, recentemente a intolerância está cada vez mais presente e agressiva principalmente pela facilidade da exposição de opiniões pela internet, assim como, pela polarização da opinião. Todavia(4), muitas vezes tais opiniões se tornam difamações a medida que os argumentos definidos sejam ilógicos e visando a inflexibilidade.

Com a espansão* dos meios de acesso à internet a diversas classes da sociedade brasileira, milhões de pessoas tem(5) contato com as redes sociais. Esta por sua vez, oportuniza a distintos comentários e discursos, em que inúmeras ocasiões não possuem embasamento lógico ou são movidos pela discriminação físico-social-cultural, gerando dessa forma, o chamado bulling*, o qual é crime punível por lei(6).

Outro ponto relevante em relação a intolerância (7), é o extremo posicionamento de opiniões (8). Hoje, principalmente com a instabilidade política nacional, como, por exemplo(9), há uma crescente polarização de ideologias, na qual existe(5) dois enfoques que seguem linhas de pensamentos totalmente contraditórios(10), ocasionando debates, conflitos e até discursos de ódio(11) utilizando acusações sem argumentos realmente convincentes. 
Tendo em vista os aspectos observados sobre a polarização das opiniões que agregam coerção na internet, especialmente nas redes sociais, a intolerância é um problema sócio-cultural grave relacionado diretamente com a discriminação e o preconceito. No entanto, este problema pode ser contornado por fortes investimentos na educação infanto juvenil*, abordando no ensino os mais distintos campos de debate e pontos de vista. Por conseguinte, o jovem poderá formar sua opinião com base em fatos concretos e argumentos procedentes, estabelecendo deveras uma sociedade nacional, afinal todos os cidadãos têm direito de serem respeitados.

1. Léo, tente explicar melhor esta afirmação. O que você quer dizer com "opinião violenta"?

2. O uso de "implicada" também não me pareceu adequado aqui.

3. A intolerância é uma convicção?

4. Este conectivo é usado para introduzir uma oposição ao que foi dito antes, o que não ocorre neste contexto. Veja se pode substituir ou omiti-lo. Penso que todo o período pode ser revisado, visando à melhor compreensão pelo leitor.

5. Revise a concordância.

6. É preciso revisar atentamente esse período de modo que sua argumentação seja mais objetiva e compreensivel ao leitor. Você pode retomar o sentido que gostaria de trazer e refletir a melhor forma de apresentá-lo, no conjunto do parágrafo. Para auxiliá-la nessa tarefa, aponto:

- oportunizar é um verbo que costuma introduzir informações positivas. Não acho que ele seja adequado aqui,

- revise a regência dos trechos em destaque, bá preposições desnecessárias;

- bá suas expressões que, se mantidas na sua reescrita, devem ficar entre vírgulas.

7. Revise a regência nesse trecho.

8. O que seria "extremo posicionamento"? Não entendi.

9. Pode ser suprimido. Há algumas expressões e conectivos ao longo do texto que, se suprimidos, podem trazer mais precisão e organização ao seu discurso. Considere isso ao revisar todo o texto.

10. A polarização já não indica contradição? Achei repetitivo esse período. Veja o que acha.

11. Você pretende apresentar consequências ruins da polarização de ideologias. Essas palavras têm, todas, efeito de sentido negativo?

12. Sua conclusão está muito bem organizada, mas é preciso melhorar a proposta de intervenção com informações mais específicas sobre o que pode ser feito. Deixo algumas perguntas para lhe ajudar nessa reflexão:

- É pertinente uma intervenção apenas na educação infanto-juvenil? Como lidar com o problema da intolerância no restante da população?

- Como podem ser aplicados esses investimentos? Será somente na escola? Qual será a abordagem?

(ex: palestras, revisão do currículo, projetos, mídia)

- Qual a responsabilidade das redes sociais nos discursos de ódio que por meio delas é propagado?

* Revisar ortografia.

É uma intervenção de revisão bastante extensa, porque se visou à abordagem completa e dialógica em cada um dos desvios identificados, para se apresentar todas as possibilidades adequadas de construção nessa perspectiva, mesmo sabendo-se dos problemas possíveis que a escolha incorre. Como discutido, a quantidade ou a extensão dos bilhetes de revisão não são condição para uma abordagem de revisão dialógica. Um breve apontamento pode promover maior interação do que um comentário extenso que esteja mal organizado. Na abordagem de proposta de revisão apresentada, os comentários foram bastante elucidativos, entretanto, considera-se 
que à medida que o aluno compreende cada etapa da produção escrita e entende $\mathrm{o}$ professor como colaborador (GERALDI, 2011; MENEGASSI; GASPAROTTO, 2019), alguns desvios podem ser abordados por meio de apontamento que mencione a natureza do desvio ou pela simples indicação com asterisco ou grifos, a servir como um alerta, um chamado à atenção do aluno para algo sobre o qual o docente sabe que o aluno tem conhecimento, mas que, por algum motivo, não observou ao redigir a primeira versão. Assim, tanto as abordagens mais estruturais de revisão (SERAFINI, 2004) como as interativas (RUIZ, 2010; NASCIMENTO, 2013; MENEGASSI; GASPAROTTO, 2016) podem servir ao propósito de um trabalho dialógico de revisão, desde que devidamente consideradas as axiologias e as especificidades do contexto imediato e do contexto mais amplo do processo de aprendizagem.

Além do nível de aprendizagem do aluno, o docente deve considerar o que se pretende a partir daquela produção textual e decidir, por exemplo, priorizar alguns desvios em detrimento de outros menos problemáticos, para que o aluno vá, aos poucos, assimilando o trabalho de revisão e não se sinta desmotivado com excessos de marcações em um único texto. Assim, é o processo de aprendizagem da escrita como um todo que orienta o caminho de revisão docente, que também muito é constituído por valorações.

Rijlaarsdam et al. (2004) ensinam que o objeto de análise deve ser os escritores e não a revisão, já que esta é realizada pelos sujeitos, para os quais o significado de cada revisão pode ser diferente. Não se pode igualar, por exemplo, um erro ortográfico de um escritor amador ao de um escritor experiente (RIJLAARSDAM et al., 2004). Assim, o aprimoramento na prática de revisão associa-se não somente a familiaridade dos revisores com determinada tarefa de revisão, mas também à capacidade do escritor em implementar os processos básicos de modelo de escrita.

\section{CONSIDERAÇÕES FINAIS}

A abordagem prática de revisão textual aqui apresentada mobilizou diversos estudos pautados no dialogismo, na escrita como trabalho e na revisão textual com intuito de apresentar uma possível proposta didática de revisão na perspectiva dialógica. A prática foi elucidada a partir da produção textual de um aluno concluinte de Curso Técnico Integrado ao Ensino Médio.

A elaboração dos bilhetes textuais e a reflexão sobre o trabalho de revisão do texto completo permitiram elucidar possibilidades de efetiva interação, por meio da revisão textual, ao docente que sustenta sua prática na perspectiva dialógica de 
ensino. Acerca dessas reflexões, destaca-se: a) a revisão textual deve ser tomada como uma produção textual por si, a considerar aspectos como referência, coesão, organização discursiva, que podem otimizar o trabalho docente e alcançar bom nível de interação com o aluno em intervenções mais precisas; b) a perspectiva dialógica demanda considerar a revisão em sua totalidade, a reconhecer o processo de interação existente entre aluno-texto-revisão-professor, haja vista a completude de sentido possível por meio do diálogo que se estabelece nas retomadas, nos vocativos, nos questionamentos que, no todo, têm a função de apontar ao aluno que a forma fragmentada de abordar os desvios é apenas um caminho estratégico para a revisão global do texto; c) uma abordagem é dialógica de acordo com a efetividade da interação estabelecida. Não se trata de quantidade ou de extensão de bilhetes de revisão, assim como, na reescrita, não se trata se quantidade de reformulações; d) o docente é responsável por reunir as axiologias e as circunstâncias linguísticas e extralinguísticas da interação para, a partir de seu juízo de valor (VOLOCHÍNOV, [1926] 2013), como professor e conhecedor do processo de imediato e amplo de aprendizagem de escrita de seu aluno, fazer as escolhas mais pertinentes; e) deve-se considerar as condições de trabalho do docente, por exemplo, em relação ao número de alunos por turma. A essas condições, o professor pode pensar estratégias (LEAL, 2003) que atendam necessidades do aluno e que também sejam viáveis àquelas condições de ensino; e) a reflexão pelo aluno sobre seu estilo de escrita, assim como a volição à revisão para além dos desvios são atitudes a serem desenvolvidas ao longo do ensino de escrita pela perspectiva do dialogismo; f) o enfoque do trabalho docente deve ser os escritores e não a revisão, já que esta é realizada pelos sujeitos, para os quais o significado de cada revisão pode ser diferente (RIJLAARSDAM et al., 2004).

Acerca da elaboração do bilhete de revisão, a análise evidenciou elementos primordiais a serem contemplados pelo docente: i) o diálogo colaborativo por meio do reconhecimento do aluno como autor; ii) a abordagem de metodologias e escolhas linguísticas, ao escrever o bilhete textual, que promovam a reflexão pelo aluno, no sentido de formá-lo revisor de seu próprio discurso; iii) a adequação da abordagem escolhida ao contexto imediato e ao contexto mais amplo, como o gênero discursivo produzido e o nível de aprendizagem do aluno; iv) o reconhecimento e a mobilização das axiologias que permeiam o evento enunciativo da revisão; v) um conjunto de revisões que aponte desvios linguísticos e discursivos, mas que também promovam desenvolvimento da consciência socioideológica do sujeito por meio da linguagem; vi) a atenção ao processo e ao progresso individual de aprendizagem do aluno, que pode, por exemplo, ser comentada nos bilhetes textuais. 
E, à estrutura do bilhete de revisão voltado a desvios discursivos, sobretudo, relacionados à argumentação, constatou-se fundamental contemplar i) apresentação do desvio; ii) justificativa, a fim de que o aluno compreenda o motivo da inadequação e, complementarmente; iii) evocação da figura do autor; iv) apresentação de reflexões, por meio de perguntas ou afirmações, que apontem caminhos para o modo como o excerto pode ser reformulado.

\section{REFERÊNCIAS}

ALLAL, L. et al. (2004). Revision of written language: cognitive and instructional processes. Boston/ Dordrecht, Netherlands/New York: Kluwer.

ANTUNES, I. (2003). Aula de Português: encontro e interação. São Paulo: Parábola.

BAKHTIN, M./VOLOCHÍINOV. ([1929] 2009). Marxismo e Filosofia da Linguagem. Tradução Michel Lahud e Yara Frateschi. 12. ed. São Paulo: Hucitec.

BAKHTIN, M. ([1979] 2010). Estética da criação verbal. 4. ed. São Paulo: Martins Fontes.

BRAIT, B. (2012). Construção coletiva da perspectiva dialógica: história e alcance teóricometodológico. In: FÍGARO, R. (Org.). Comunicação e análise do discurso. São Paulo: Contexto, v. 1, p. 79-98.

BREIDENBACH, K. Practical guidelines for writers and teachers. (2006). In: HORNING, A.; BECKER, A. (Orgs). Revision: History, theory, and practice. West Lafayette, Indiana: Parlor Press and The WAC Clearinghouse, p. 197-219.

CAMPS, A. (2006). Texto, processo, contexto, atividade discursiva: diferentes pontos de vista sobre a atividade de aprender e de ensinar a escrever. In: CAMPS, A. (Org.); Propostas didáticas para aprender a escrever. Porto Alegre: Artmed, p. 13-32.

FIAD, R. S.; MAYRINK-SABINSON, M. L. T. (1991). A escrita como trabalho. In: MARTINS, M. H. (org.). Questões da Linguagem. São Paulo: Contexto, p. 54-63.

GARCEZ, L. H. C. (1998). A escrita e o outro: os modos de participação na construção do texto. Brasília: Editora Universidade de Brasília.

GASPAROTTO, D. M.; MENEGASSI, R. J. (2015). Aspectos da prática docente na revisão e reescrita de narrativa de terror. Fórum Linguístico. Florianópolis, v.12, n.3, p.808-826. 
GERALDI, J. W. (Org.). ([1984] 2011). O texto na sala de aula. Cascavel: Assoeste.

HAYES, J. R. What triggers revision?. (2004) In: ALLAL et al. Revision: Cognitive and instructional processes. Kluwer Academic Publishers Dordrecht, p.9-20.

KENN, J. (2010). Strategic revisions in the writing of Year 7 students in the UK. The Curriculum Journal, v. 21, p. 255-280.

LEAL, L. F. V. (2003). A Formação do Produtor de Texto Escrito na Escola: uma análise das relações entre os processos interlocutivos e os processos de ensino. In: VAL, M. da G. C.; ROCHA, G. (Orgs.). Reflexões sobre práticas escolares de produção de texto: o sujeito autor. Belo Horizonte: Autêntica/CEALE/FaE/UFMG, p. 53-67.

MENEGASSI, R. J. (1998). Da revisão à reescrita: operações e níveis linguísticos na construção do texto. Tese (Doutorado em Letras) - Universidade Estadual Paulista Júlio de Mesquita Filho, Assis.

MENEGASSI, R. J. (2016). A escrita como trabalho na sala de aula. In: JORDÃO, C. M. A Linguística Aplicada no Brasil: rumos e passagens. 1 ed. Campinas: Pontes, p. 193-230.

MENEGASSI, R. J.; GASPAROTTO, D. M. (2016). Revisão textual-interativa: aspectos teórico-metodológicos. DOI: 10.14393/DL23-v10n3a2016-13. Domínios de Linguagem. Uberlândia, v. 10, n. 3, p. 1019-1045.

MENEGASSI, R. J. (2019). Revisão Dialógica: princípios teórico-metodológicos. DOI: 10.1590/1982-4017-190107-4518. Linguagem em Dis(curso) - LemD, Tubarão-SC, v. 19, n. 1, p. 107-124.

NASCIMENTO, C. E. (2013). Os bilhetes orientadores da reescrita e a aprendizagem relatório de experiência. In: GONÇALVES, Adair Vieira \& BAZARIM, Milene. Interação, gêneros e letramento: a (re)escrita em foco. São Paulo: Pontes Editores.

POSSATI, J. (2013). A reescrita dialógica. Dissertação de mestrado. Campinas: Unicamp.

RIJLAARSDAM G. et al. (2004). The study of revision as a writing process and as a learning-to-write process. In: ALLAL et al. Revision: Cognitive and instructional processes. Kluwer Academic Publishers Dordrecht, p. 189-207.

RUIZ, E. D. (2010). Como corrigir redações na escola. São Paulo, Contexto.

SERAFINI, M. T. (2004). Como escrever textos. São Paulo: Globo. 
SOBRAL, A. (2009). Do Dialogismo ao gênero: as bases do pensamento do círculo de Bakbtin. Campinas: Mercado das Letras.

TRUPPIANO, C. (2006). Best classroom practices. In: HORNING, A.; BECKER, A. (Orgs.). Revision: History, theory and practice. West Lafayette, In: Parlor Press and The WAC Clearinghouse, p. 177-196.

VOLOCHÍNOV, V.N. ([1926] 2013). Palavra na vida e a palavra na poesia. Introdução ao problema da poética sociológica. In: A construção da enunciação e outros ensaios. São Carlos: Pedro e João Editores, p. 71-100.

Recebido: 6/12/2019

Aceito: $1 / 6 / 2020$

Publicado: 20/7/2020 